\title{
Load Voltage and Frequency Regulation in PMSG based Standalone Wind Energy Conversion System
}

\author{
Md. Asif \\ Vardhaman College of Engine \\ Shamshabad
}

\author{
Sardar Ali \\ Royal Institute of Technology \\ Chevella
}

\author{
N. Sambasiva Rao \\ SR College of Engineering \\ Warangal
}

\begin{abstract}
Stand alone variable speed wind energy conversion system with PMSG is proposed in this paper. Two back to back VSCs are connected to interface PMSG with load. Constant voltage in DC link between two VSCs can be maintained constant by using a battery energy storage system (BESS). BESS is efficient to maintain load voltage and frequency to be regulated during variable wind speed conditions. MPPT based vector controlling is used to control generator side converter to maintain unity power factor at PMSG which improves generated power and efficiency. Load side converter is controlled to maintain regulated voltage and frequency at load side. Simulations are performed using MATLAB/SIMULINK to check effectiveness of control strategies. Performance is checked with increase in wind speed; decrease in wind speed and with unbalanced/non linear loads.
\end{abstract}

\section{Keywords}

PMSG, wind energy, MPPT, Battery Energy storage, voltage source converters.

\section{INTRODUCTION}

Wind energy conversion system is economically feasible and environment friendly in power generation. Because of its environmental benefits, technological advance and government incentives wind energy conversion is growing fast from last decade. Annual growth rate of wind energy conversion is $40 \%$ during last 15 years. Wind turbines are designed either for constant wind speed or for variable wind speed. Comparing with constant speed wind turbines, $10 \%$ to $20 \%$ more output can be gained from variable speed wind turbines. Power electronic converters are required in between wind generation and utility side to maintain regulated voltage and frequency at load side [1].

Depends on the type of wind turbines three types of generators are utilised in wind energy conversion. Squirrel cage induction generator (SCIG) is coupled to a fixed speed wind turbine through a gear box and is directly connected to grid. Doubly fed induction generator (DFIG) is coupled to variable speed wind turbine through a gear box and its stator is directly connected to grid. Rotor windings of DFIG are fed by power electronic converters to control rotor frequency and hence rotor speed. Third type of generator is a low speed high torque synchronous generator (PMSG) [2]. PMSGs are gaining popularity in wind energy conversion system due to their self excitation property, high efficiency, reduced weight and compact construction. Because of no requirement of mechanical components such as slip rings reliability of conversion increases.

Controlling of variable wind speed turbine with doubly fed induction generator is presented in [3]. Rating of power converters in such type of conversion depends on speed range.
PMSG based variable speed wind energy conversion system is presented in [4]. In this configuration load is connected to PMSG through a diode rectifier and a DC chopper. Controlling of power factor at generator side is not possible which reduces efficiency of generator. Harmonic distortion at generator side is also high because of diode rectifier. In [5], a $\mathrm{z}$ source inverter is connected to grid for PMSG based wind energy conversion system. Matrix converters are best alternative to back to back converters [6]. These converters can convert variable $\mathrm{AC}$ to constant $\mathrm{AC}$ to match the grid requirement. But main disadvantage of matrix converter is number of switches are high and hence switching losses are more and controlling is more complicated [7].

Adaptive MPPT algorithms are essential to know the optimal operating point of wind turbines [8]. Different types of MPPT algorithms including TSR control, optimal torque control, Power signal feedback control and perturbation and observation control are studied in [9-10]. Performance of tip speed ratio control is very efficient during variable wind speed condition.

In this paper PMSG based standalone wind energy conversion system is connected to load through two back to back VSCs. Control strategies for two converters are proposed to maintain regulated voltage and frequency at load side. A battery energy storage system is connected at DC link of two converters to regulate DC side voltage.

\section{SYSTEM CONFIGURATION}

Fig 1. Shows PMSG based wind energy conversion system with two VSCs and a BESS in DC link. Generator side converter is connected to three phase terminals of PMSG; load side converter is connected to unbalanced/non linear loads through a star delta transformer for neutral terminal. Transients at load side due to switching of LSC are reduced by a high pass RC filter.

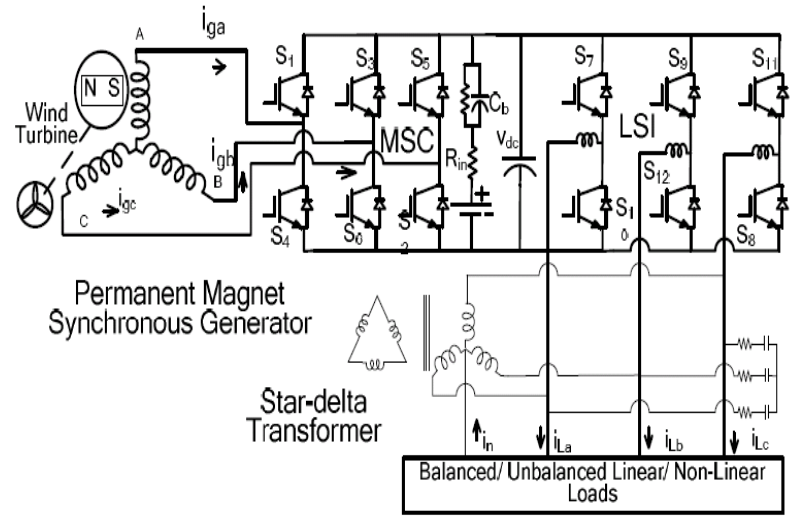

Fig 1: System Configuration 


\subsection{Wind Turbine Modelling}

Mechanical torque developed by wind turbine is given by

$\mathrm{T}_{\mathrm{m}}=\frac{1}{2} \rho \pi \mathrm{R}_{\mathrm{t}}^{2} \mathrm{C}_{\mathrm{p}}(\lambda, \beta) \frac{\mathrm{V}^{3}}{\Omega_{\mathrm{r}}}$

Where $\lambda=\frac{R_{\mathrm{t}} \Omega_{\mathrm{r}}}{\mathrm{V}}$

$\rho$ is the air density, Rt is the radius of the turbine, $\Omega \mathrm{r}$ is the rotational speed of turbine rotor in $\mathrm{rad} / \mathrm{sec}$., $\lambda$ is top speed ratio, $\beta$ is pitch angle and $\mathrm{Cp}$ rotor power coefficient.

An empirical expression for $C_{p}(\lambda, \beta)$ is

$$
\begin{aligned}
& C_{p}=[0.5-0.00167(\beta-2)] \\
& \sin \left(\frac{\pi(\lambda+0.1)}{12-0.3(\beta-2)}\right)-0.00184(\beta-2)(\lambda-3)
\end{aligned}
$$

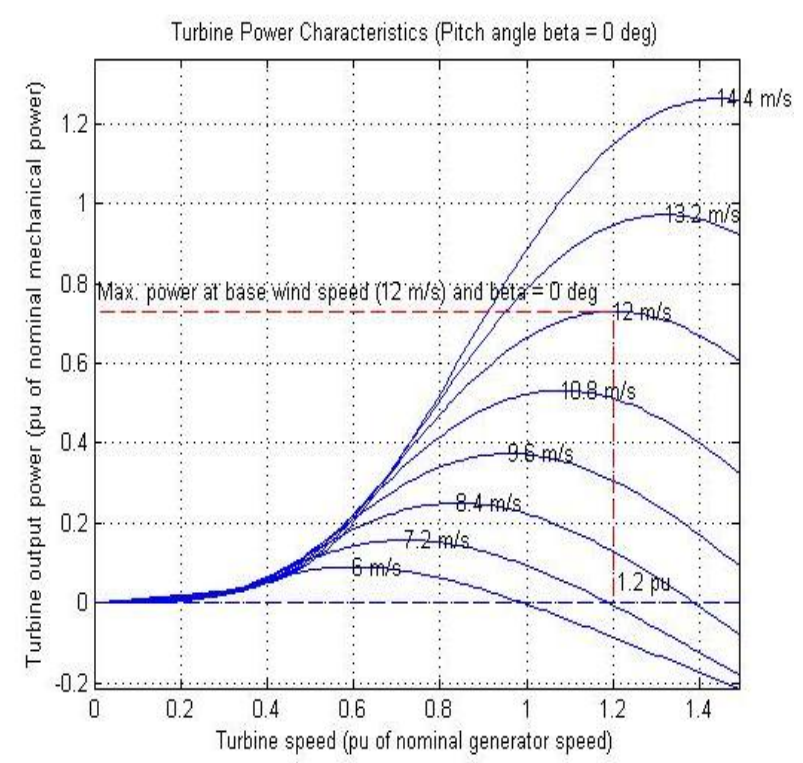

Fig 2: Wind Turbine Characteristics

Relation between turbine output power and turbine speed is shown in fig 2. from these characteristics optimum power for maximum energy for a particular wind speed can be determined. For a wind speed always there is a turbine speed to achieve maximum turbine power.

\subsection{Drive train model}

A drive train consists of blade pitching mechanism, rotor shaft, spinner, a hub with blades. By considering drive train as spring connected discrete masses with damping and stiffness coefficients, the equation of ith mass motion described as

$\frac{\mathrm{d}^{2} \theta_{\mathrm{i}}}{\mathrm{dt}^{2}}=\frac{\mathrm{v}_{\mathrm{i}} \mathrm{c}_{\mathrm{i}}}{\mathrm{J}_{\mathrm{i}}} \frac{\mathrm{d} \theta_{\mathrm{i}-1}}{\mathrm{dt}}-\frac{\mathrm{v}_{\mathrm{i}+1}^{2} \mathrm{c}_{\mathrm{i}+1}+\mathrm{c}_{\mathrm{i}}}{\mathrm{J}_{\mathrm{i}}} \frac{\mathrm{d} \theta_{\mathrm{i}}}{\mathrm{dt}}+\frac{\mathrm{v}_{\mathrm{i}} \mathrm{k}_{\mathrm{i}}}{\mathrm{J}_{\mathrm{i}}} \theta_{\mathrm{i}-1}-\frac{\mathrm{v}_{\mathrm{i}+1}^{2} \mathrm{k}_{\mathrm{i}+1}+\mathrm{k}_{\mathrm{i}}}{\mathrm{J}_{\mathrm{i}}} \theta_{\mathrm{i}}+$ $\frac{v_{i+1} k_{i+1}}{J_{i}} \theta_{i+1}+\frac{\tau_{i}}{J_{i}}-D_{i} \frac{d \theta_{i}}{d t}$

$\mathrm{Vi}$ is transmission rate between $\mathrm{i}$ and $\mathrm{i}-1$ masses

$\mathrm{Ci}$ is shaft viscosity $[\mathrm{kg} / \mathrm{ms}]$

$\mathrm{Ki}$ is shaft elastic constant $[\mathrm{N} / \mathrm{m}]$

$\mathrm{J}$ is moment of inertia of ith mass [kg.m2]

Ti is external torque [N.m] applied to the ith mass

Di is damping coefficient $[\mathrm{N} . \mathrm{m} / \mathrm{s}]$

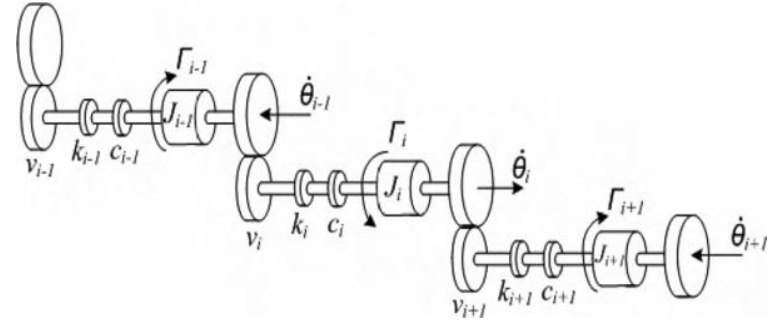

Fig 3: Transmission model of $\mathbf{N}$ masses

Study of torsional fatigue has to consider dynamics of all parts. But to simplify the modelling drive train is treated as one lumped mass model during interaction between wind farms and $\mathrm{AC}$ grids. Hence drive train model can be simplified by following equation

$$
\frac{\mathrm{d} \omega_{\mathrm{g}}}{\mathrm{dt}}=\frac{\tau_{\mathrm{e}}-\tau_{\mathrm{w} \_\mathrm{g}}}{\mathrm{J}_{\mathrm{eq}}}-\frac{\mathrm{B}_{\mathrm{m}}}{\mathrm{J}_{\mathrm{eq}}} \cdot \omega_{\mathrm{g}}
$$

Where $g$ is the parameter of the generator side, $\omega_{\mathrm{g}}$ is the mechanical angular speed, $B_{m}$ is damping coefficient, $\tau_{e}$ is the electromechanical torque, $\tau_{\mathrm{w}_{-} \mathrm{g}}$ is the aerodynamic torque, $\mathrm{J}_{\mathrm{eq}}$ is the equivalent rotational inertia.

\subsection{MPPT Algorithm}

Even with variable wind speed tip speed ratio is constant for a wind turbine. By choosing optimal value for TSR maximum energy can be extracted from wind turbine. Characteristics between coefficient of power and TSR are shown in fig 4 . During variable wind speed error between optimal TSR and actual TSR force the conversion system to change speed of the generator to maintain reduced error.

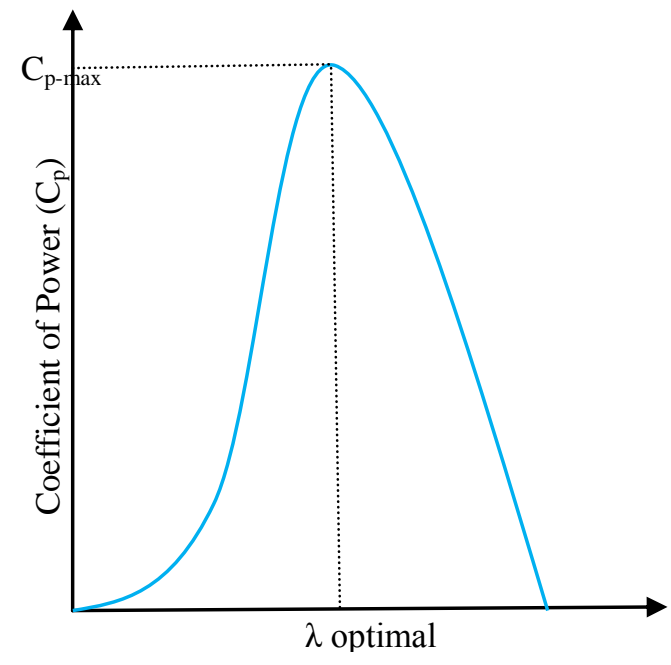

Tip Speed Ratio $\lambda$

Fig 4: Characteristics between coefficient of power and TSR

\subsection{PMSG model}

Using Synchronous reference frame two axis based dynamic model of PMSG can be derived. Following assumptions are taken while deriving the mathematical model of PMSG. Damping windings are not considered. Considering stator winding is symmetrical. Neglect dependency of rotor inductance on rotor position due to stator slots. Neglect damping windings. Consider resistances of all windings are constant and neglecting capacitance. Position of stator winding is sinusoidal along the air gap while considering 
mutual effect with rotor. Mathematical model of PMSG in synchronous reference frame can be given as

$\left[\begin{array}{c}\mathrm{U}_{\mathrm{d}} \\ \mathrm{U}_{\mathrm{q}}\end{array}\right]=\left[\begin{array}{cc}\mathrm{R}_{\mathrm{s}} & 0 \\ 0 & \mathrm{R}_{\mathrm{s}}\end{array}\right]\left[\begin{array}{l}\mathrm{I}_{\mathrm{d}} \\ \mathrm{I}_{\mathrm{q}}\end{array}\right]+\frac{\mathrm{d}}{\mathrm{dt}}\left[\begin{array}{l}\phi_{\mathrm{d}} \\ \phi_{\mathrm{q}}\end{array}\right]+\omega_{\mathrm{r}}\left[\begin{array}{c}-\phi_{\mathrm{q}} \\ \phi_{\mathrm{d}}\end{array}\right]$

Where $\phi_{\mathrm{d}}=\mathrm{L}_{\mathrm{d}} \mathrm{I}_{\mathrm{d}}+\phi_{\mathrm{r}}$

$\phi_{\mathrm{q}}=\mathrm{L}_{\mathrm{q}} \mathrm{I}_{\mathrm{q}}$

In state equation form PMSG is modelled as

$\frac{\mathrm{dI}_{\mathrm{d}}}{\mathrm{dt}}=\frac{1}{\mathrm{~L}_{\mathrm{ds}}+\mathrm{L}_{\mathrm{ls}}}\left(-\mathrm{R}_{\mathrm{s}} \mathrm{I}_{\mathrm{d}}+\omega_{\mathrm{r}}\left(\mathrm{L}_{\mathrm{qs}}+\mathrm{L}_{\mathrm{ls}}\right) \mathrm{I}_{\mathrm{q}}+\mathrm{U}_{\mathrm{d}}\right)$

$\frac{\mathrm{dI}_{\mathrm{q}}}{\mathrm{dt}}=\frac{1}{\mathrm{~L}_{\mathrm{qs}}+\mathrm{L}_{\mathrm{ls}}}\left(-\mathrm{R}_{\mathrm{s}} \mathrm{I}_{\mathrm{q}}-\omega_{\mathrm{r}}\left(\left(\mathrm{L}_{\mathrm{ds}}+\mathrm{L}_{\mathrm{ls}}\right) \mathrm{I}_{\mathrm{d}}+\phi_{\mathrm{r}}\right)+\mathrm{U}_{\mathrm{q}}\right)$

Its torque equation is given as

$\tau_{\mathrm{e}}=1.5 \mathrm{p}\left(\left(\mathrm{L}_{\mathrm{ds}}-\mathrm{L}_{\mathrm{ls}}\right) \mathrm{I}_{\mathrm{d}} \mathrm{I}_{\mathrm{q}}+\mathrm{I}_{\mathrm{q}} \phi_{\mathrm{r}}\right.$

\section{CONTROL ALGORITHM}

Controlling scheme of both the VSCs connected at generator side and load side is shown in fig 5 and 6 . Main objective of load side converter is to maintain regulated voltage with constant frequency and should maintain low harmonic distortion and balanced voltages. Generator side converter should extract maximum power from wind generation using MPPT and should maintain unity power factor at generator side. Flux oriented control for aligning stator flux with D axis is taken as controlling algorithm at generator side.

\subsection{Control of Generator-side Converter}

Stator flux oriented control is taken for generator side converter which uses synchronous reference frame. Mechanical sensor measures rotor speed and angle. Reference speed of PMSG can be generated from measured wind speed using wind turbine characteristics. Reference speed and actual speed of PMSG are compared and error is given to PI controller to get active power component.

$\omega_{\mathrm{e}}(\mathrm{n})=\omega_{\mathrm{r}}^{*}(\mathrm{n})-\omega_{\mathrm{r}}(\mathrm{n})$

$I_{g q}^{*}(n)=I_{g q}^{*}(n-1)+K_{p \omega} \omega_{e}(n)+K_{i \omega} \omega_{e}(n)(9)$

Reactive component of current of PMSG should be maintained zero to maintain unity power factor at generator side. Hence d axis component of PMSG current should be zero.

$\mathrm{I}_{\mathrm{gd}}^{*}=0$

For three phase to two phase conversion, the transformation angle $\left(\theta_{\text {re }}\right)$ is obtained as follows,

$\theta_{\text {re }}=\frac{\mathrm{P}}{2} \theta_{\mathrm{r}} \square \square \square \square \square \square \square \square$

where $\mathrm{P}$ is number of poles of PMSG.

Reference PMSG currents are obtained from $\mathrm{I}_{\mathrm{gd}}^{*}$, $\mathrm{I}_{\mathrm{gq}}^{*}$ and $\theta_{\text {re }}$ as follows

$\mathrm{i}_{\mathrm{ga}}^{*}=\mathrm{I}_{\mathrm{gd}}^{*} \sin \left(\theta_{\mathrm{re}}\right)+\mathrm{I}_{\mathrm{gq}}^{*} \cos \left(\theta_{\mathrm{re}}\right)$

$\mathrm{i}_{\mathrm{gb}}^{*}=\mathrm{I}_{\mathrm{gd}}^{*} \sin \left(\theta_{\mathrm{re}}-2 \pi / 3\right)+\mathrm{I}_{\mathrm{gq}}^{*} \cos \left(\theta_{\mathrm{re}}-2 \pi / 3\right)$

$\mathrm{i}_{\mathrm{gb}}^{*}=\mathrm{I}_{\mathrm{gd}}^{*} \sin \left(\theta_{\mathrm{re}}+2 \pi / 3\right)+\mathrm{I}_{\mathrm{gq}}^{*} \cos \left(\theta_{\mathrm{re}}+2 \pi / 3\right)$

Current errors are generated from these three reference currents and actual PMSG currents and the error is compared with a carrier signal to generate the pulses for generator side converter.

\subsection{Control of Load-side Inverter}

Voltage and frequency of load side should be regulated by load side converter.

For regulated voltage and frequency at load side effective controlling of load side converter is essential. Reference values of load voltages can be obtained as

$\mathrm{U}_{\mathrm{La}}^{*}(\mathrm{t})=\mathrm{U}_{\mathrm{m}} \sin (2 \pi \mathrm{ft})$

$\mathrm{U}_{\mathrm{Lb}}^{*}(\mathrm{t})=\mathrm{U}_{\mathrm{m}} \sin (2 \pi \mathrm{ft}-120)$

$\mathrm{U}_{\mathrm{Lb}}^{*}(\mathrm{t})=\mathrm{U}_{\mathrm{m}} \sin (2 \pi \mathrm{ft}+120)$

$\mathrm{U}_{\mathrm{m}}$ is the reference amplitude of load voltage.

These three reference voltages are compared with actual sensed voltages $\mathrm{U}_{\mathrm{La}}, \mathrm{U}_{\mathrm{Lb}}$ and $\mathrm{U}_{\mathrm{Lc}}$ and given to PI controller to generate reference load side converter currents.

$$
\begin{aligned}
& \mathrm{U}_{\text {Laer }}(\mathrm{t})=\mathrm{U}_{\mathrm{La}}^{*}(\mathrm{t})-\mathrm{U}_{\mathrm{La}}(\mathrm{t}) \\
& \mathrm{U}_{\text {Lber }}(\mathrm{t})=\mathrm{U}_{\mathrm{Lb}}^{*}(\mathrm{t})-\mathrm{U}_{\mathrm{Lb}}(\mathrm{t}) \quad(20) \\
& \mathrm{U}_{\text {Lcer }}(\mathrm{t})=\mathrm{U}_{\mathrm{Lc}}^{*}(\mathrm{t})-\mathrm{U}_{\mathrm{Lc}}(\mathrm{t}) \quad(21) \\
& \mathrm{i}_{\mathrm{LSIa}}^{*}(\mathrm{t})=\mathrm{i}_{\mathrm{LSIa}}^{*}(\mathrm{t}-1)+\mathrm{K}_{\mathrm{p}}\left\{\mathrm{U}_{\text {Laer }}(\mathrm{t})-\mathrm{U}_{\text {Laer }}(\mathrm{t}-1)\right\}+ \\
& \mathrm{K}_{\mathrm{i}} \mathrm{U}_{\text {Laer }}(\mathrm{t}) \quad(22) \\
& \mathrm{i}_{\mathrm{LSIb}}^{*}(\mathrm{t})=\mathrm{i}_{\mathrm{LSSb}}^{*}(\mathrm{t}-1)+\mathrm{K}_{\mathrm{p}}\left\{\mathrm{U}_{\text {Lber }}(\mathrm{t})-\mathrm{U}_{\text {Lber }}(\mathrm{t}-1)\right\}+ \\
& \mathrm{K}_{\mathrm{i}} \mathrm{U}_{\text {Lber }}(\mathrm{t}) \quad(23) \\
& \mathrm{i}_{\text {LSIc }}^{*}(\mathrm{t})=\mathrm{i}_{\text {LSIc }}^{*}(\mathrm{t}-1)+\mathrm{K}_{\mathrm{p}}\left\{\mathrm{V}_{\text {Lcer }}(\mathrm{t})-\mathrm{U}_{\text {Lcer }}(\mathrm{t}-1)\right\}+ \\
& \mathrm{K}_{\mathrm{i}} \mathrm{U}_{\mathrm{Lcer}}(\mathrm{t}) \quad(24)
\end{aligned}
$$

These three reference currents are compared with actual sensed load side currents. Amplitude of the error between reference and actual currents can be adjusted by controller gain. These current errors are compared with carrier signal to generate switching signals for LSI.

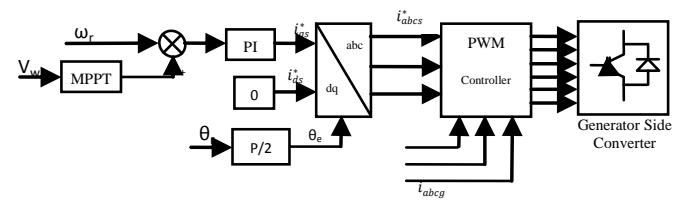

Fig 5: Control strategy for generator side converter

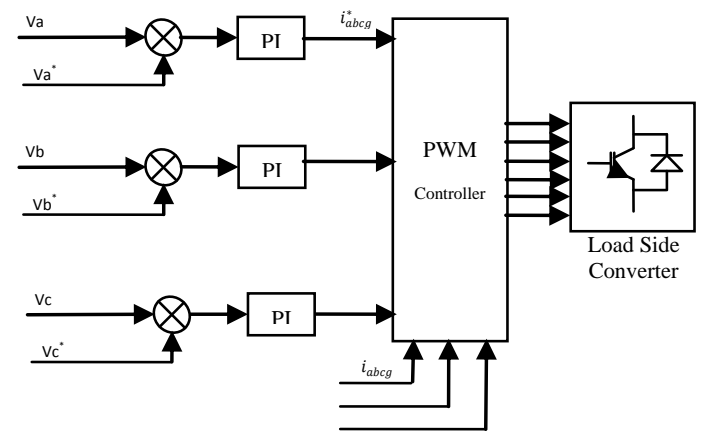

Fig 6. Control strategy for load side converter

\section{SIMULATION RESULTS}

To check the performance of standalone PMSG with control strategy simulations are carried out for increase in and decrease in wind speed and for linear/ nonlinear loads. 


\subsection{Decrease in wind speed}

In this case performance of PMSG is evaluated during decrease in wind speed. Balanced linear load is connected to load side converter. Upto $1.5 \mathrm{sec}$ of simulation wind speed is $12 \mathrm{~m} / \mathrm{s}$ then speed is reduced to $8 \mathrm{~m} / \mathrm{s} .7 .1 \mathrm{rad} / \mathrm{s}$ is speed of PMSG upto $1.5 \mathrm{sec}$ for wind speed of $12 \mathrm{~m} / \mathrm{s}$, then speed will reduced to $4 \mathrm{rad} / \mathrm{sec}$ due to fall in wind speed as shown in fig 8. This is because of MPPT algorithm, which provides new reference rotor speed and actual rotor speed tracks this change in reference rotor speed. Stator current of PMSG is shown in fig 7. Linear load of $16 \mathrm{KW}$ with 0.9 lagging pf is connected at load side. Decrease in wind speed reduces the amount power generated by PMSG as shown in fig 13. Because of energy storage system connected in DC side will maintain the load voltage to be constant. Hence load cannot be disturbed because of variation in wind speed. Constant load voltage and current are shown in fig 9. Magnitude and frequency of load voltage is shown in fig 12 .

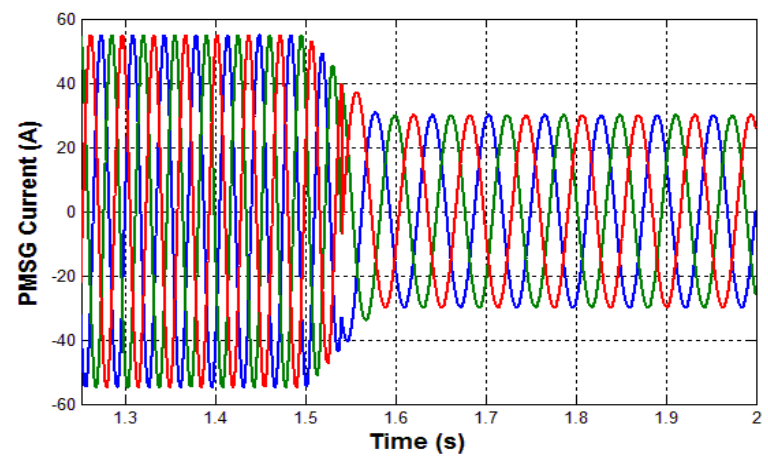

Fig 7: PMSG Current during change in wind speed
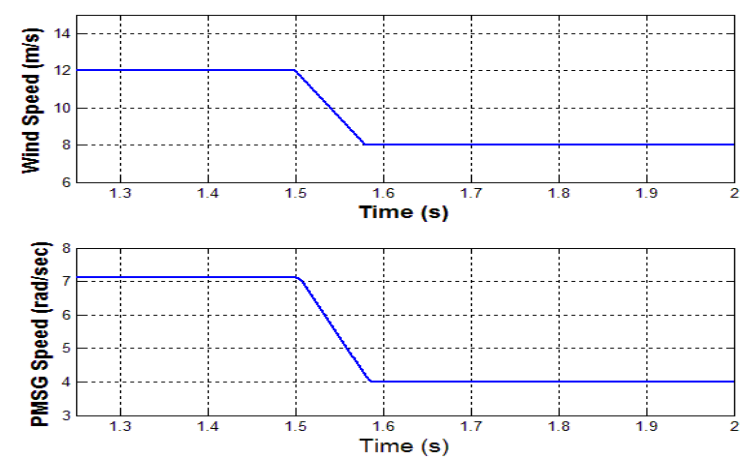

Fig 8. change in wind speed and PMSG speed
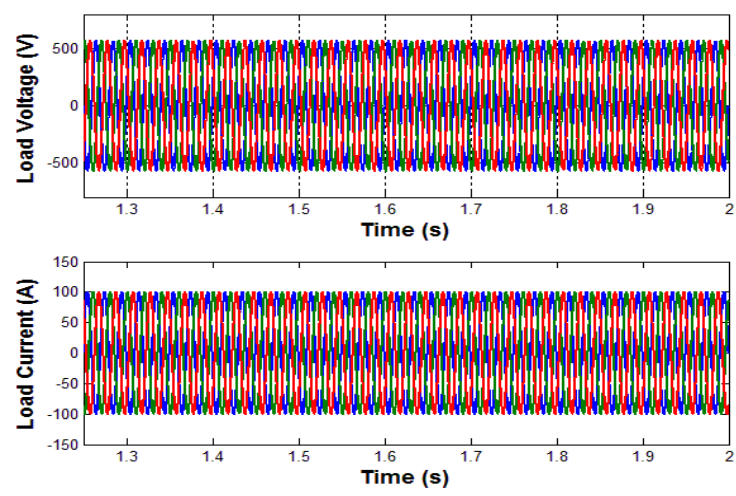

Fig 9: load voltage and current for change in wind speed
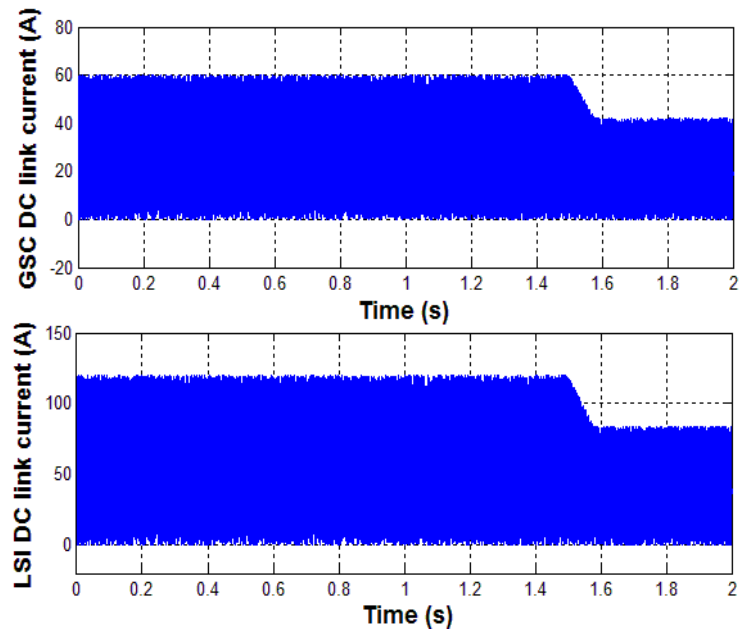

Fig 10: DC link Currents of PMSG side and load side
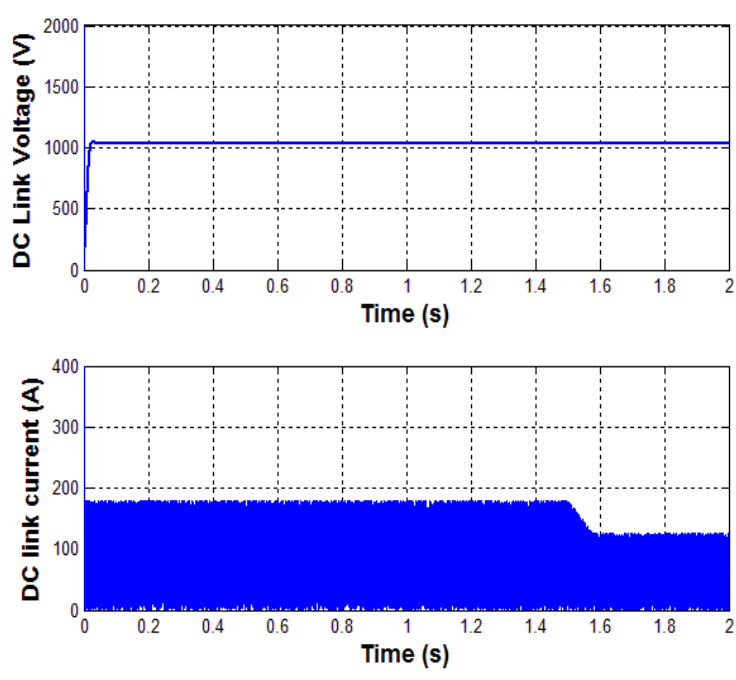

Fig 11: DC link voltage and current
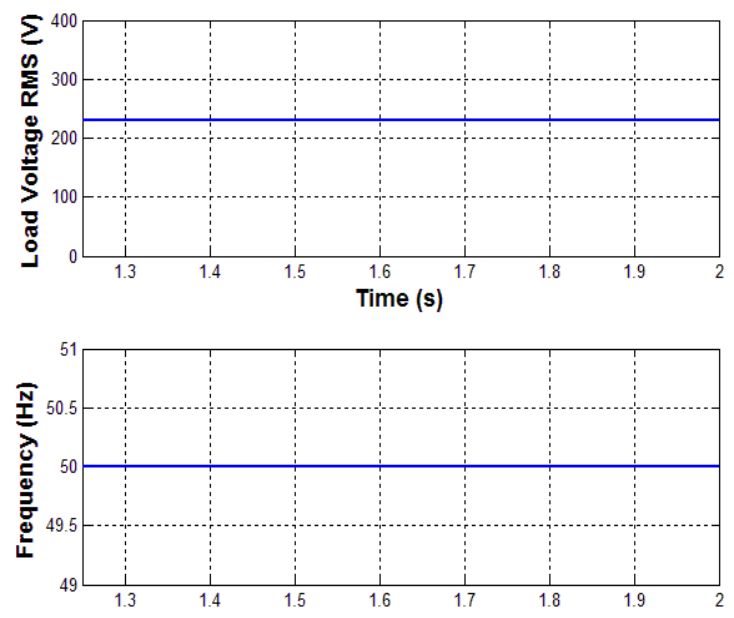

Fig 12. Load voltage and frequency of load voltage 


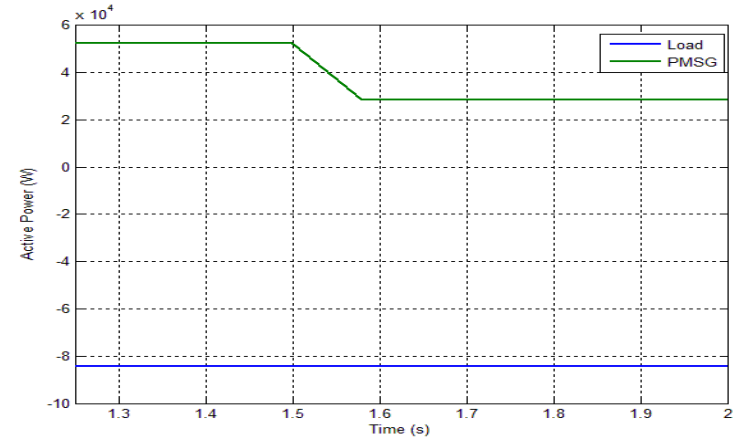

Fig 13. Load and PMSG Active power

\subsection{Increase in wind speed}

In this case wind speed is increased from $8 \mathrm{~m} / \mathrm{s}$ to $12 \mathrm{~m} / \mathrm{s}$ at 3 seconds. Increase in wind speed increases reference rotor speed by MPPT, then actual speed tracks this increase in reference speed. Fig 14 and 15 shows wind speed and rotor speed. Increase in wind speed increases the power generated by PMSG, hence PMSG stator current also changes. But due to constant load this increase in generation can be stored in energy storage system. Load voltage and load current are shown in fig 17. Constant voltage and increased current of BESS due to wind speed are shown in fig 19.

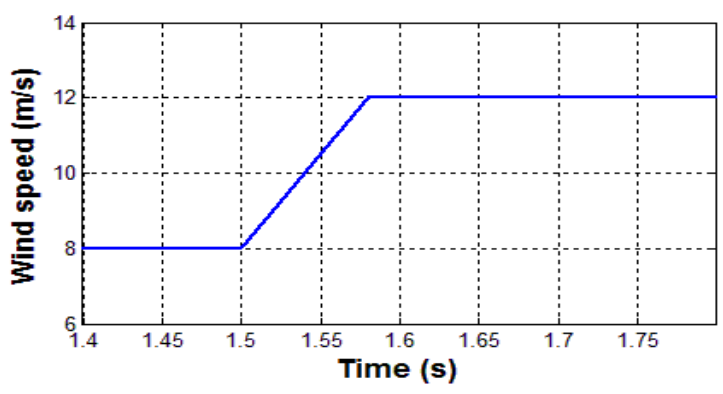

Fig 14: Increase in wind speed

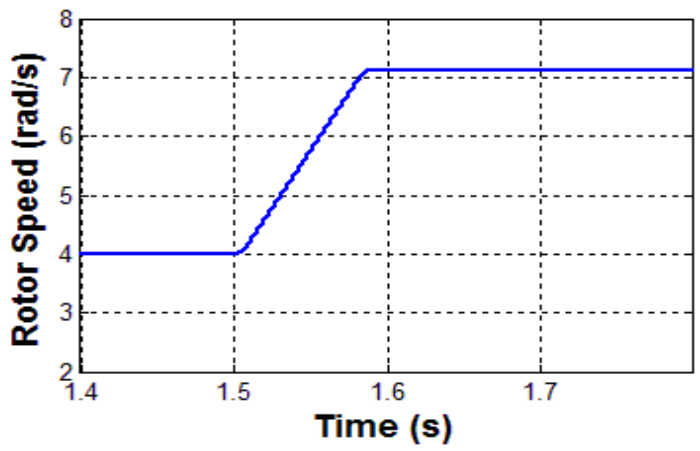

Fig 15: Change in rotor speed

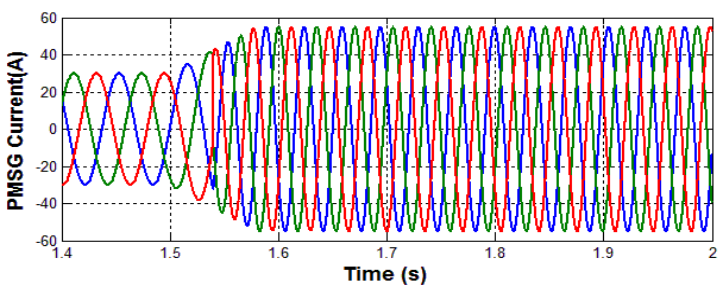

Fig 16: PMSG Current during increase in wind speed

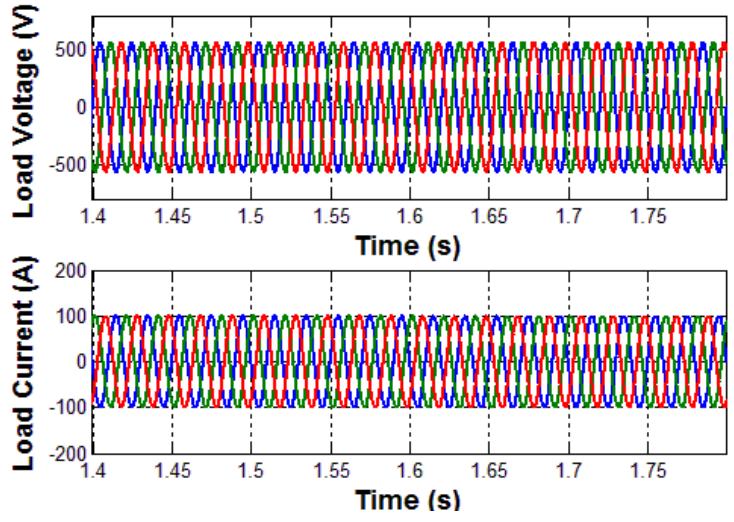

Fig 17: Load voltage and current
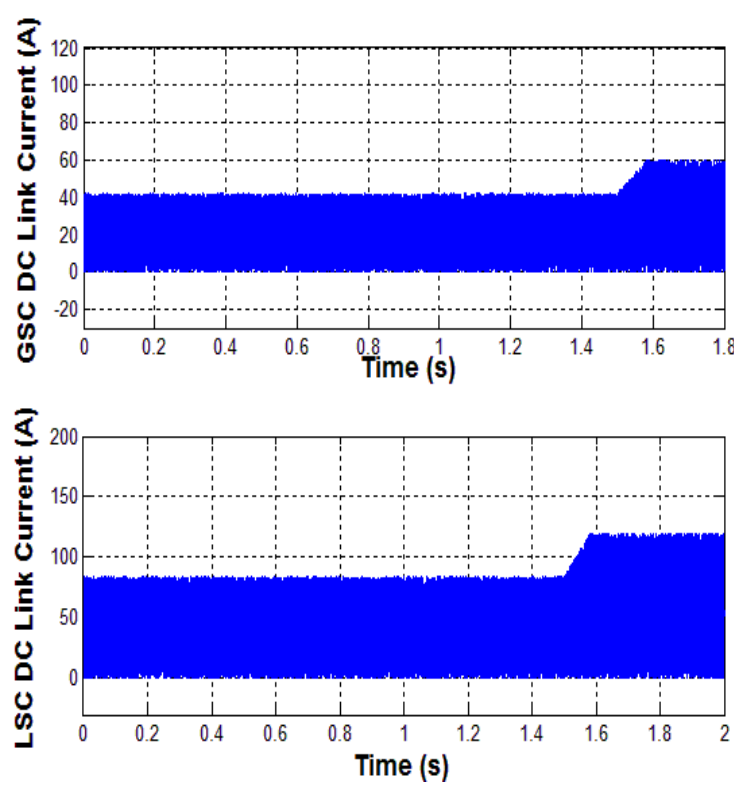

Fig 18. Generator side and load side DC currents
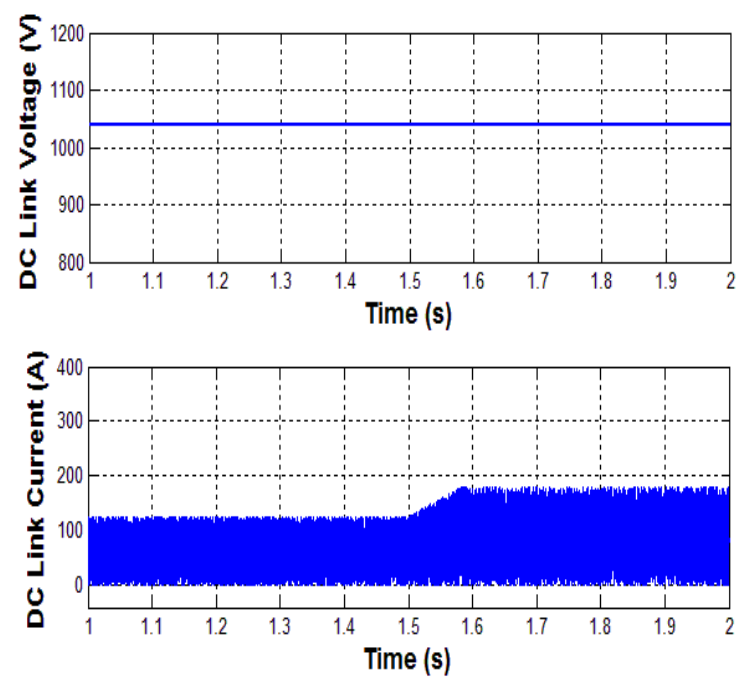

Fig 19. Voltage and current of BESS 


\subsection{Constant wind speed with unbalanced nonlinear loads.}

In this case wind speed is maintained at constant value of 12 $\mathrm{m} / \mathrm{s}$ and load is changed to unbalanced non linear load. Three single phase diode rectifier loads are connected to each phase. Load in phase a is removed from $0.2 \mathrm{sec}$ to $0.4 \mathrm{sec}$. And load in phase $\mathrm{b}$ is removed from $0.25 \mathrm{sec}$ to $0.4 \mathrm{sec}$. Even with unbalanced load, load voltage shown in fig 21 is maintained constant because of control strategy of load side converter. Effect of unbalanced and harmonic currents of load on PMSG stator currents is almost negligible due to DC link between load and PMSG. Stator currents are shown in fig 20. Amplitude and frequency of load voltage are maintained constant as shown in fig 23. Total harmonic distortion of load current is $36 \%$ and load voltage is maintained at $1.5 \%$.

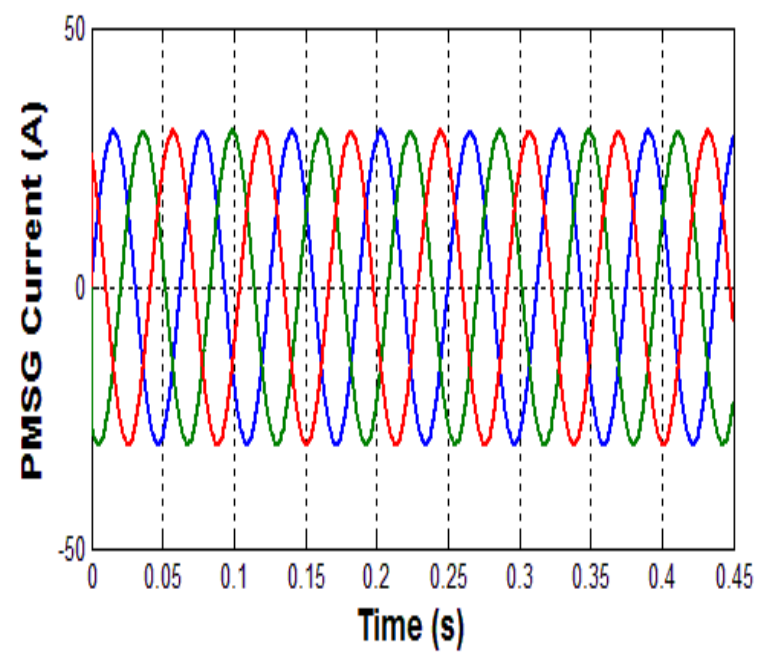

Fig 20. PMSG Current

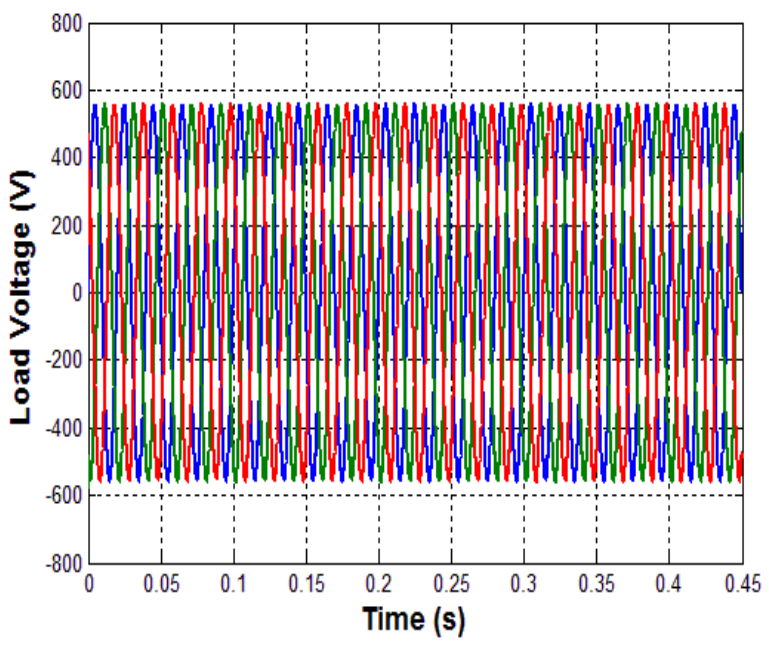

Fig 21. Load Voltage
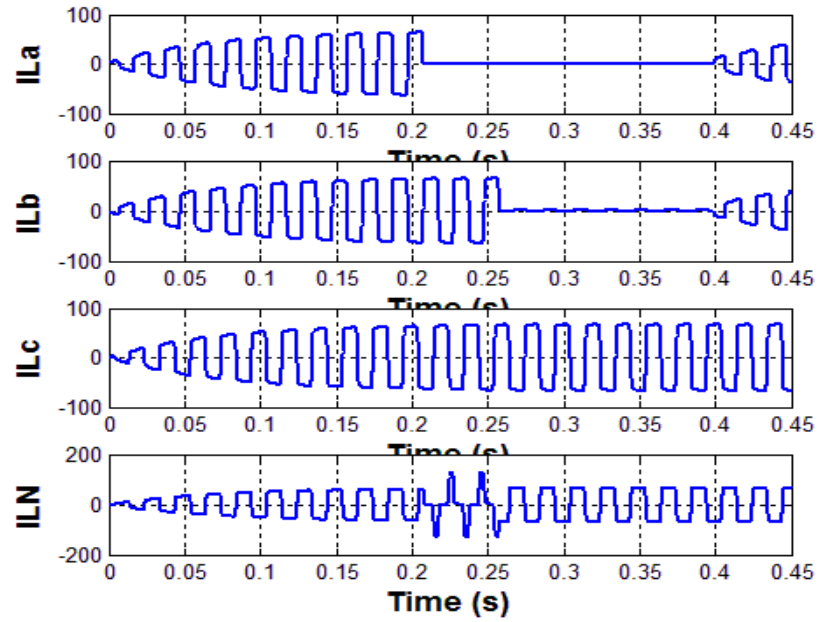

Fig 22. Load Currents
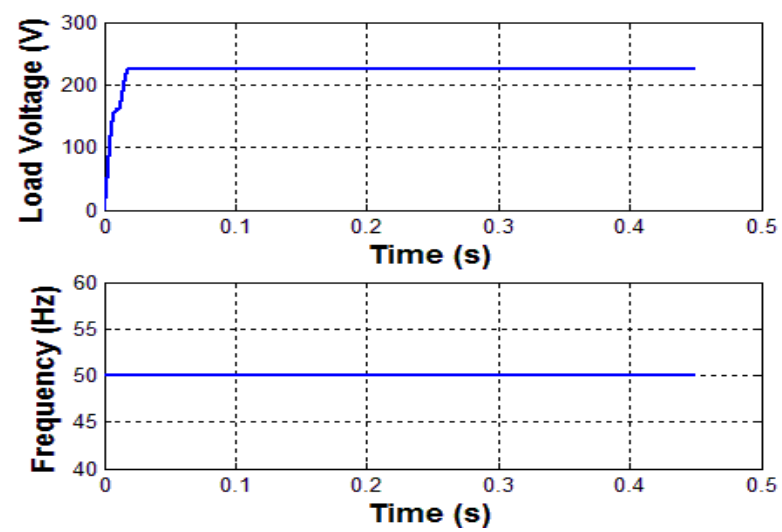

Fig 23. Load voltage magnitude and frequency

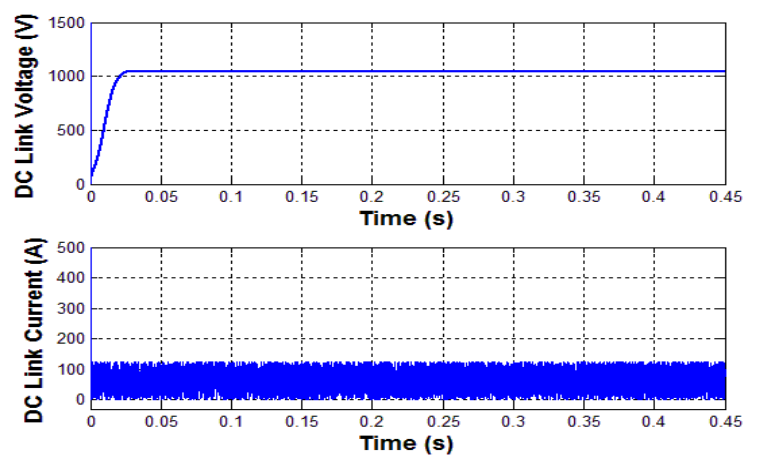

Fig 24. Voltage and current of BESS

\section{CONCLUSION}

A new configuration with two back to back VSCs is proposed to regulate load voltage and frequency in a PMSG based stand alone wind energy conversion system. DC link between two back to back VSCs are connected to a Battery Energy Storage System. Unity power factor operation at PMSG is achieved by MPPT based control strategy applied to generator side converter. Even during hange in wind speeds load voltage and frequency are regulated by control strategy applied to load side converter. 


\section{REFERENCES}

[1] Liuchen Chang, "Wind Energy Conversion Systems" University of N. Brunswick, NB, IEEE Canadian Review - Spring / Printemps

[2] H. Li Z. Chen, "Overview of different wind generator systems and their comparisons" IET Renew. Power Gener., 2008, Vol. 2, No. 2, pp. 123-138

[3] F. Blaabjerg, M. Liserre , K. Ma "Power Electronics Converters for Wind Turbine Systems" IEEE Transactions on Industry Applications · October 2011

[4] R. Pena, J. C. Clare, and G. M. Asher, "Doubly fed induction generator using back-to-back PWM converters and its application to variable-speed windenergy generation,” Proc. Inst. Elect. Eng.-Elect. Power Appl., vol. 143, no. 3, pp. 231-241, May 1996.

[5] Z. Chen and E. Spooner, "Simulation of a direct drive variable speed energy converter," in Proc. Int. Conf. Electrical Machines, Istanbul, Turkey, 1998, pp. 20452050.

[6] H Hojabri, H Mokhtari, L Chang, "Stand Alone Performance of Permanent Magnet Synchronous Wind
Power Generator with Current Source Matrix Converter", Electric Power Components and Systems Volume 43, Issue 8-10, 2015

[7] Abdullah M.A., Yatim A.H.M., Tan C.W., Saidur R. "A review of maximum power point tracking algorithms for wind energy systems" Renewable and Sustainable Energy Reviews 16 (2012) 3220-3227

[8] Feng X, Jianzhong Z, Ming C. Analysis of double objectives control for wind power generation system with frequency separation. In: 2011 4th International Conference on Electric Utility Deregulation and Restructuring and Power Technologies (DRPT). 2011. p. 1366-71.

[9] M. E. Haque, M. Negnevitsky and K.M. Muttaqi, "A Novel Control Strategy for a Variable-Speed Wind Turbine With a Permanent-Magnet Synchronous Generator," IEEE Trans. Industry Appl., vol. 46, no. 1, pp. 331 - 339, Jan. /Feb. 2010.

[10] B. Wu, Y. Lang, N. Zargari, and S. Kouro, Power Conversion and Control of Wind Energy Systems, 1st ed. Wiley-IEEE Press, July 2011. 